\title{
TU/e emonownen

\section{A decision support system for location and allocation problems within a brewery}

\section{Citation for published version (APA):}

van Nunen, J. A. E. E., \& Benders, J. F. (1981). A decision support system for location and allocation problems within a brewery. (Memorandum COSOR; Vol. 8119). Technische Hogeschool Eindhoven.

\section{Document status and date:}

Published: 01/01/1981

\section{Document Version:}

Publisher's PDF, also known as Version of Record (includes final page, issue and volume numbers)

\section{Please check the document version of this publication:}

- A submitted manuscript is the version of the article upon submission and before peer-review. There can be important differences between the submitted version and the official published version of record. People interested in the research are advised to contact the author for the final version of the publication, or visit the $\mathrm{DOI}$ to the publisher's website.

- The final author version and the galley proof are versions of the publication after peer review.

- The final published version features the final layout of the paper including the volume, issue and page numbers.

Link to publication

\section{General rights}

Copyright and moral rights for the publications made accessible in the public portal are retained by the authors and/or other copyright owners and it is a condition of accessing publications that users recognise and abide by the legal requirements associated with these rights.

- Users may download and print one copy of any publication from the public portal for the purpose of private study or research.

- You may not further distribute the material or use it for any profit-making activity or commercial gain

- You may freely distribute the URL identifying the publication in the public portal.

If the publication is distributed under the terms of Article 25fa of the Dutch Copyright Act, indicated by the "Taverne" license above, please follow below link for the End User Agreement:

www.tue.nl/taverne

Take down policy

If you believe that this document breaches copyright please contact us at:

openaccess@tue.nl

providing details and we will investigate your claim. 
EINDHOVEN UNIVERSITY OF TECHNOLOGY

Department of Mathematics and Computing Science

Memorandum COSOR $81-19$

A Decision Support System for

location and allocation

problems within a brewery

by

Jo van Nunen *

and

Jacq Benders

to appear in DGOR-Operations Research Proceedings,

1981, Springer Verlag, Berlin.

De1ft, October 1981

* Graduate School of Management Delft.

** University of Technology Eindhoven, Department of Mathematics and Computing Science. 
by

Jo van Nunen, Graduate School of Management, Delft

and

Jacq Benders, University of Technology, Eindhoven.

Abstract In this paper we describe a decision support system that was developed for supporting strategical and tactical decision making with respect to location of warehouses and the allocation of customers to warehouses. The system is currently used by the Department of "physical distributions" within Heineken breweries to help management with mid- and longterm logistic decisions. The core of the system is a large mixed integer linear programming model. This paper containes a (long) abstract of the research carried out. A complete description of the results will be submitted for publication elsewhere.

\section{Introduction}

The use of mathematical models for supporting decisions concerning the distribution structure . within a brewery is not new. The first models were probably used at the operational level to support routing decisions. Nowadays software packages for this kind of problems are commercially available. In recent years several systems were developed to support managerial decisions, concerning the distribution structure, at the strategical and tactical level. Many of these systems involve large mixed integer linear programs see e.g. (1), (2), (3). However, the size of these problems was such that the required computational effort often formed a bottleneck. Among others, we can say that the fast development and increase in speed, of the current generation of computers, enables the use of large scale (mixed integer) linear programs within a decision support system. In this paper we hope to give an illustration of the above statement.

We will start by giving a restricted mathematical problem formulation. Thereafter we will describe the type of questions that is involved for distribution problems at the tactical and strategical level. Next the requirements to be put upon a decision support system will be indicated. The mixed integer linear program is formulated and the system that was built around it is discussed.

\section{Problem formulation}

In order to understand the problems that will be discussed later on we will first give a simplified problem formulation. Roughly speaking the model is based on a distribution network like the one given in figure 1. 
Breweries

Production lines

Warehouses

Buyers

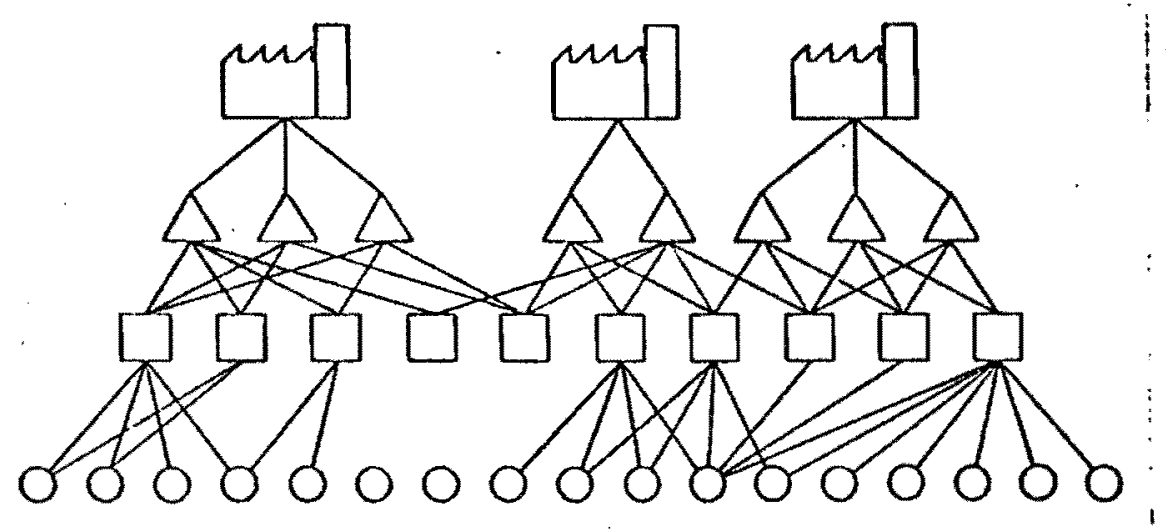

Figure 1. Simplified distribution network for the location allocation problem.

In the above network each brewery consists of a number of production lines. Each production line can produce one or several of the $n$ products that are considered. The products have to be transported to and stored in warehouses which are located at different places in the country. The buyers which are themselves wholesalers have to be supplied from the warehouses. It is requested for practical reasons that each Buyer is assigned to exactly one warehouse for all his products. The demand of the buyers is supposed to be known. In the actual situation(s) the forecasts for the demand in the main season were rather adequate for mid- en long term planning goals. The maximum time that a product is allowed to be in a warehouse is limited.

The mathernatical problem might be formulated as follows: which warehouse, out of a given potential set of warehouses should be used. How should the available buyers be allocated to these warehouses, such that, within the capacity constraints of lines and warehouses, the costs for production, handling and transportation ăre minimal.

The above problem formulation requires in fact the determination of the amount of each product that has to be transported from each production line to each warehouse. Moreover, it requires for each buyer the determination of the warehouse he is assigned to.

Since the demand is supposed to be known, the determination of the transportation and assignment variables enables us to deduce from them directly, how much each production line should produce of a given product, how much of each product should be stored in each warehouse etc.

As constraints we encountered capacity restriction for the warehouses and the production lines. In addition, the production time at the different production lines was requested to be more or less equal in order to avoid big differences in the load of older and newer lines. The maximal throughput time of beer in warehouses was equal to 3 weeks for bottles and 1 week for casks. This upperbound of three weeks is due to internal Heineken regulations for the maximal time that beer is allowed to spend in their warehouses. In fact, this throughput time is a control variable. Since, reductions from 3 to e.g. 2.7 weeks means that more buyers can be assigned to a warehouse. The required space for a ton of a certain product was warehouse 
dependent. Moreover transportation costs are not linear with respect to the distance.

Problems of the above type are described in several articles in literature, see (1), (2). In this paper we will report some of our experiences with the application and implementation of the developed decision support system, and describe the (mixed integer) linear program that was used.

From a managerial point of view the problem formulation, given so far, is too restrictive. In the practical situation we meet questions of the type:

- What are the consequences of closing the (old) bottle lines of the brewery in Amsterdam.

- What are the consequences if we open a new depot in Venlo.

- What will be the profit of an extension of one specific warehouse.

- What are the consequences with respect to costs, production storage and assignment of buyers if the demand for $30 \mathrm{cl}$. bottles increases with $6 \%$ while the demand for $50 \mathrm{cl}$. bottles decreases with $4 \%$.

- What are the consequences if the handling costs in a large warehouse decrease with $5 \%$ while in smaller warehouses there is an increase in these costs of $10 \%$.

- What are the consequences if we use line 1 only for the production of $30 \mathrm{cl}$. bottles.

- etc.

Questions of the above type have to be answered fast in order to evaluate alternative scenarios and to support the negotiations between the department of "physical distribution" and the departments of production, marketing etc. Consequently, a number of questions arise in the designing phase of the system which are concerned with the way in which the system information should be transformed and presented such that it suits the specific decision making process within the organization.

Examples of such questions are:

- In which way can we meet the specific requirements that are set by other departments. This holds as well for the specific information as for the form in which this should be offered to fit the way in which the decision making process evolves in that department.

- What is the best aggregation level of the information for several hierarchical levels in the organization.

- Which options should be built in the system in order to force the user to consider aspects which are not explicitly incorporated in the model. Often these aspects are of a qualitative character.

- What are the way's of personal decision making of the involved managers and how should this be encountered.

The above type of questions shows that from a managerial point of view the specific operations research problem formulations as given earlier is only a small part of the practical problem. In order to give sufficient support for a practical problem one has to strive after a 
synthesis between the relevant points of view, like the point of view of the managers, the behavioral scientists, the computer scientist, the operations research scientist, etc. This approach is described by Keen and Scott Morton in their book on Decision Support Systems (4). The relevance of a multidisciplinary approach is also advocated in the literature which is concerned with the practical use of Operations Research and Management information systems.

However, the Decision Support System Approach (re)emphasizes the role of a support system within the overall decision making process which includes in practical situations many qualitative aspects.

In this abstract we will not report in detail about the DSS that was developed, although a rough outline is given. Some of the problems that were encountered and some of the applications, will be mentioned in the final section. However, we will first describe the mathematical model in some more detail. This is done since the modular model formulation formed the basis of the system and created the technical possibilities for evaluating alternative scenario's.

\section{Modelformulation}

For the modelformulation we will use the notation which was developed for this specific situation and which was kept during the development of the DSS. Maintaining a consistent notation proved to be more or less essential for an easy technical processing as well as for user friendly options for report generation and for model and data base manipulation.

The input of the system is based on four lists with names.

\begin{tabular}{|c|c|c|c|}
\hline $\begin{array}{l}\text { model name } \\
\text { of the list }\end{array}$ & name & contents & \\
\hline $\mathbf{p}$ & Products & The names of the different products & . \\
\hline $\mathrm{L}$ & Lines & The names of the different production lines & \\
\hline W & Warehouses & The names of the different warehouses & \\
\hline $\mathrm{B}$ & Buyers & The names of the different Buyers & \\
\hline
\end{tabular}

Figure 2. Basic-lists for the location-allocation model.

Based on this list we have the relevant input tables given in figure 3. The contents of most of the tables will be clear immediately. An exception might be EGINLP $(1, p)$ which contains the egalization indices for handling. the differences between old and new production lines and CONVPW $(p, w)$ which is used to indicate the differences in space that is required for storing one ton of product $p$ in warehouse $w$. 


\begin{tabular}{|c|c|c|}
\hline Table & Name & Descriptions \\
\hline DBP (b,p) & Demand $(b, p)$ & The demand of buyer $p$ for product $p$. \\
\hline $\operatorname{TCL} W(1, w)$ & Transportation costs $(b, w)$ & $\begin{array}{l}\text { The transportation costs for one ton } \\
\text { of product from buyer } \mathrm{b} \text { to } \mathrm{w} \text {. }\end{array}$ \\
\hline HCPW $(p, w)$ & Handling costs $(p, w)$ & $\begin{array}{l}\text { The handling costs for one ton of } \\
\text { warehouse product } p \text { in warehouse } w \text {. }\end{array}$ \\
\hline $\operatorname{PCLP}(1, \mathrm{p})$ & Production costs $(1, \mathrm{p})$ & $\begin{array}{l}\text { The production costs of one ton of } \\
\text { product } p \text { at line } 1 \text {. }\end{array}$ \\
\hline CAPLP $(1, p)$ & Capacity $(1, p)$ & $\begin{array}{l}\text { The production capacity of line } 1 \text { with } \\
\text { respect to product } p \text {. }\end{array}$ \\
\hline EGINLP $\left(1_{: p}\right)$ & Egalization index $(1, \mathrm{P})$ & $\begin{array}{l}\text { Egalization index of line } 1 \text { for pro- } \\
\text { duct p. }\end{array}$ \\
\hline UPCAPW (w) & Uppercapacity (w) & $\begin{array}{l}\text { The maximal capacity of ware- } \\
\text { house w. }\end{array}$ \\
\hline LOCAPW (w) & Lower capacity (w) & $\begin{array}{l}\text { The minimal capacity that should be } \\
\text { used in warehouse w. }\end{array}$ \\
\hline THRUPW $(p, w)$ & Throughput time $(p, w)$ & $\begin{array}{l}\text { The maximal throughput time of } \\
\text { product } p \text { in warehouse } w \text {. }\end{array}$ \\
\hline CONVPW $(p, w)$ & Conversion index $(p, w)$ & $\begin{array}{l}\text { The conversion index for space occu- } \\
\text { pation of product } p \text { in warehouse } w \text {. }\end{array}$ \\
\hline
\end{tabular}

Figure 3. Notation of the input tables for the location allocation model.

Most of the data required for the tables of figure 3 could be selected from a data base that was available within Heineken breweries. From the above data we deduced the quantities listed in figure 4.

\begin{tabular}{|c|c|}
\hline Table & Description \\
\hline TPL $(p, 1)$ & Time required to produce 1 ton of product $\mathrm{p}$ on line 1 , after egalization. \\
\hline CAPBW $(b, w)$ & Capacity required to store the full demand of buyer $b$ in warehouse $w$. \\
\hline CPLW $(p, 1, w)$ & $\begin{array}{l}\text { Costs for production, handling and transportation of } 1 \text { ton of product } p \\
\text { from line } 1 \text { to warehouse } w \text {. }\end{array}$ \\
\hline$C B W(b, w)$ & $\begin{array}{l}\text { Cost for handling and transportation of the demand of buyer } b \text { from ware- } \\
\text { house } w \text { to buyer } b \text {. }\end{array}$ \\
\hline
\end{tabular}

Figure 4. Some additional input tables for the location allocation model.

The model formulation can now be given by means of the decision variables. The first group of decision variables contains the transportation variables:

TPLW $(p, 1, w) \quad$ The amount of product $p$ that has to be produced on line 1 for transportation to warehouse w.

The second group contains the assignment variables:

ASBW $(b, w) \quad A 0-1$ variable, which is 1 when buyer $b$ is assigned to warehouse $w$ and 0 otherwise. 
The following type of restrictions had to be satsfied:
BALPV $(p, w)$
The balancing restrictions which guarantee that the amount of product $p$
- that is transported to $w$ is equal to the demand for product $p$ in warehouse w.
CAPUL (1) The production capacity restriction for lines, which guarantee that (ega- lized) production capacity for line 1 is not violated.
CAPUW (W)
CAPLLW $(w)$
The capacity restrictions for the warehouses, which guarantee
ASRB (b) that the maximum (minimum) capacity of warehouse $w$ is not violated.
The assignment restriction which guarantees that buyer $b$ is assigned to just one warehouse.

The problem formulation can now be stated as the determination of the decision variables TPLW $(\mathrm{p}, 1, \mathrm{w})$ and ASBW $(\mathrm{b}, \mathrm{w})$ such that the total production, handling and transportation costs are minimal. These costs are represented in the object function COST.

The structure of the mixed integer linear program is for an example with 2 warehouses, 3 products, 3 production lines and 4 buyers given in figure 5.

In this tableau we used some slightly different notations of which the explanation can be found in figure 6. In figure 6 , which formed the starting point for our modular matrix generation, we define in a systematic way the coefficients in the mixed integer linear programming model (MILP) which are non-zero.

The size of the problem is determined by the number of decision variables and the number of restrictions. The number of decision variables equals (number of $P$ ) $x$ (number of $W$ ) $x$ (number of $\mathrm{L}$ ) $+($ number of $B) \times$ (number of $W$ ). The number of restrictions is (number of $P$ ) $*$ (number of $W)+($ number of $L)+(2 *$ number of $W)+($ number of $B)$.

In a practical situation with 10 products, 20 lines, 50 potential warehouses and 900 Buyers this yields a MILP with 55.000 columns and 1.520 rows. Solving such large systems is even with the current technology only possible if we use the problem structure in an efficient way. For this, a specialized know-how in the areas of computer science as well as Operations Research is a necessity. The modularity and efficiency was not only required for finding solutions in an acceptable time but also for creating the possibilities for fast changes in the model as well as in the parameters. The cpu time of a computer run varied from 3 minutes for a "first run" to less than 30 seconds if a starting basis for the simplex procedure was provided. 


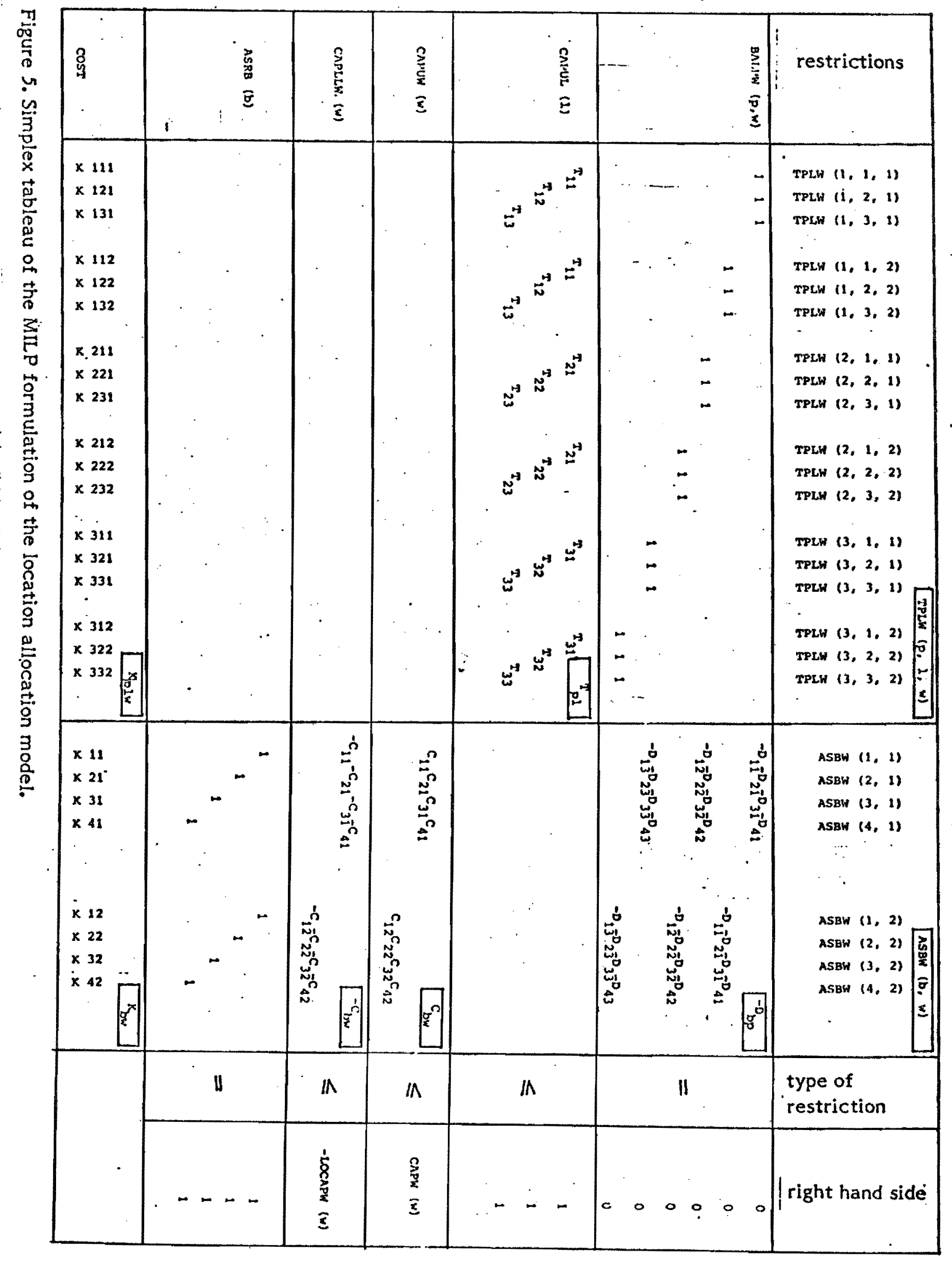




\begin{tabular}{|c|c|c|c|c|}
\hline column & row & matrixelement & relation & notation fig. 5 \\
\hline TPLW $(p, 1, w)$ & $\begin{array}{l}\text { BALPW }(p, w) \\
\text { CAPUL (1) } \\
\text { COST }\end{array}$ & $\begin{array}{l}1 \\
\operatorname{TPL}(p, 1) \\
\operatorname{KPLW}(p, 1, w)\end{array}$ & & $\begin{array}{l}T_{p l} \\
K_{p l w}\end{array}$ \\
\hline ASBW $(b, w)$ & $\begin{array}{l}\text { BALPW }(p, w) \\
\text { CAPUW }(w) \\
\text { CAPLLW (w) } \\
\text { ASRB (b) } \\
\text { COST }\end{array}$ & $\begin{array}{l}-\operatorname{DBP}(b, p) \\
\operatorname{CBW}(b, w) \\
-\operatorname{CBW}(b, w) \\
1 \\
\operatorname{CBW}(b, w)\end{array}$ & & $\begin{array}{l}-D_{b p} \\
c_{b w} \\
-c_{b w} \\
k_{b W}\end{array}$ \\
\hline RHS & $\begin{array}{l}\operatorname{BALPW}(p, w) \\
\text { CAPUL }(1) \\
\text { CAPUW }(w) \\
\text { CAPLLW }(w) \\
\operatorname{ASRB~(b)}\end{array}$ & $\begin{array}{l}0 \\
1 \\
\operatorname{CAPH}(W) \\
-\operatorname{LOCAPW}(W) \\
1\end{array}$ & $\begin{array}{l}= \\
\leqslant \\
\leqslant \\
\leqslant \\
=\end{array}$ & \\
\hline
\end{tabular}

Figure 6. Definition of the non-zero coëficients in the simplex tableau of the location allocation model.

Normally problems with more than 45.000 zero-one variables are only solvable if a lot of special structure is available. In this case we solved the problem first as a "normal" linear programming problem. In the resulting solutions there were only a relatively small amount of assignment variables which were not zero or one. An efficiënt upperbound for this number can be given. From this point on we proceed with an heuristic, to determine a feasible integer solution which was in general within $0.1 \%$ of the LP solution. So for practical goals this was more than sufficient.

\section{The decision support system}

The previous action might suggest that the majority of the research was concerned with the modelformulation process and technical difficulties. However, in the introductary sections we indicated already that a practical system should offer the possibilities for supporting questions from different departments and different hierarchical levels within the organization. In order to support the decision process it is requested that alternative scenarios can be evaluated and compared. This requires a system in which based on a master data base different problem inputs can be selected. The input of additional data for a specific problem definition can partly be done in a conversational way. Also the selection of an actual problem formulation and the 


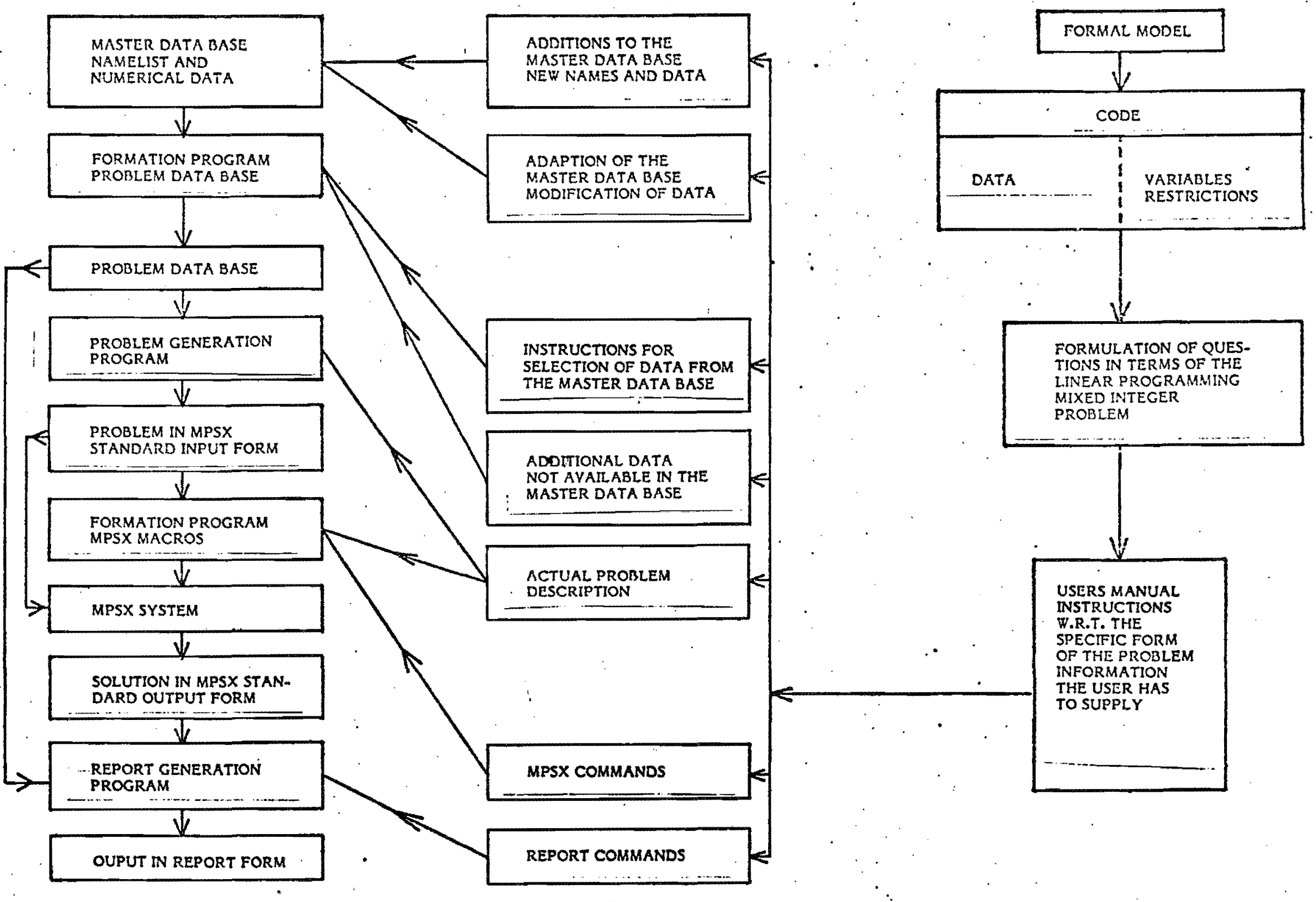

Figure 7 Structure of the decision support system. 
selection of reports out of a large set of possible reports can be done conversationally via a terminal. A rough outline of the decision support system is given in figure 7 . Note that the MPSX-package forms only a relatively small part of the total system.

5. Some final comments about implementation of the DSS for location allocation problems.

The developed system has been used by the department of physical distribution of the Heineken organization a number of times for the evaluation of specific mid-and long-term policies with respect to distribution structures. Each evaluation required a number of computer runs. Some applications are

- An analysis of the expedition structure 1980 for Heineken beer for the Netherlands;

- An analysis of the production and distribution structure for 1983;

- An analysis of a centralized versus a decentralized distribution structure for beer in the Netherlands;

- An analysis of the distribution structure for Heineken owned soft drinks in the Netherlands;

- An analysis of production and distribution structure for Heineken owns beer in Italy;

- etc.

Without discussing the ultimate decisions one can say that the information provided by the developed system had significant influence at the planning proposals that were produced, where the possibilities for making a quick evaluation of alternatives proved to be essential.

Finally we would like to extend our sincere thanks to ir. G. Stolk of Heineken whose cooperation was essential for the success of the research. We are indebted to our colleagues W. Keulemans and ir. L.R. van Vliet who developed the technical part of the system.

\section{References}

(1) A.M. Geoffrion and G.W. Graves, Multicommodity Distribution System Design by Benders Decomposition. Management Science, 20 (1974), pp. 822-844.

(2) A.M. Geoffrion, A Guide to Computer-Assisted Methods for Distribution Systems Planning. Sloan Management Review, 16 (1975), pp. 17-41.

(3) P.S. Bender, W.B. Northup and J.F. Shapiro, Practical Modelling for Resource Management. harvard Business Review, 81 (1981), pp. 163-173.

(4) P.G.W. Keen and S. Scott-Morton, Decision Support Systems, an organizational perspective. Addison Wesley Publ. Comp. (1978), London.

(5 J.F. Benders and J.A.E.E. van Nunen, $\Lambda$ decision support system for location and allocation problems within a brewery. Informatie 11 (1981) (in dutch). 